\title{
THE EFFECT OF COPPER AND IRON IONS ON THE GROWTH OF THE BLADDERWORTS UTRICULARIA GIBBA AND U. MACRORHIZA
}

\author{
Sunipa SaHa And Douglas W. Darnowski • Department of Biology • Washington College • 300 \\ Washington Avenue • Chestertown MD 21620 USA・ssaha2@washcoll.edu
}

Keywords: chemistry: habitat — field studies: Utricularia gibba, U. macrorhiza.

\author{
Introduction
}

In this paper, we examine correlations between the concentrations of metal ions, specifically copper as $\mathrm{Cu}^{2+}$ and iron as $\mathrm{Fe}^{3+}$, and the growth characteristics of two aquatic bladderworts (Utricularia gibba and U. macrorhiza). Our work involved field observations at several Utricularia sites in the Middle Atlantic States (USA), transplant studies at two locations within one marsh, and laboratory analyses.

Copper and iron are both micronutrients required for healthy growth in plants (Raven, 1971). Metal ions dissolved in $\mathrm{H}_{2} \mathrm{O}$ form metal hydroxides and hydronium ions, making the solution acidic. In such acidic solutions, decomposition of plant matter is slowed, leading to a deficiency of nutrients and minerals (Kosiba, 1992).

Copper was chosen for study because, while it is a necessary micronutrient, in high concentrations it can be harmful to plants (Raven, 1971). In addition, many of the sites visited were surrounded by farmland where agricultural fertilization practices are likely to result in elevated copper concentrations in surface water. Iron was chosen for study because there were two areas in one marsh in our sample where old iron construction equipment lay. Presumably, the iron ion concentrations are elevated in these sites.

We hypothesized that the bladderworts' growth rates would increase with higher concentrations until the amount of metal ions became toxic for the plants, causing either a decrease in growth rate or death.

\section{Methods}

During a ten week period, weekly field excursions were made to a variety of sites. Measurements were taken at these locations for $\mathrm{pH}$, salinity, temperature, nitrate, and both total light intensity and photosynthetic active radiation. Copper levels at these sites ranged from 0.55 to $1.7 \mu \mathrm{g}$ $\mathrm{L}^{-1}$ (mean value: $0.79 \mu \mathrm{g} \mathrm{L}-1$, standard deviation $0.33 \mu \mathrm{g} \mathrm{L}^{-1}$ ) while iron levels ranged between 0.12 and $2.9 \mu \mathrm{g} \mathrm{L}^{-1}$ (mean value: $1.3 \mu \mathrm{g} \mathrm{L}^{-1}$, standard deviation $0.94 \mu \mathrm{g} \mathrm{L}^{-1}$ ).

Water samples were collected at each site, and the copper and iron levels were measured using the colorimetric Neocuproine and Phenanthroline methods, respectively (Greenberg, et al., 1992). In the Neocuproine method, the absorbance was measured at $457 \mathrm{~nm}$, while for the Phenanthroline method, the orange-red complex was analyzed at $510 \mathrm{~nm}$ (Standard Methods, 1992).

Transplantation experiments were run at Big Marsh, Maryland (also known as Echo Hill). Seven permanent sites were chosen at Big Marsh as described in McDermott \& Darnowski (2001), and in this paper we use the same set of site \# locations (Sites \#1-7). Two of the sites (\#1, \#5) were adjacent to rusting iron equipment, and we theorized these sites might have elevated iron levels in the water.

Six specimens of $U$. macrorhiza and six specimens of $U$. gibba were selected from a population we maintain in our greenhouse. These plants originally came from sites \#5 and \#7 (i.e. twelve plants total). Their initial masses and lengths of the main stem were recorded. Each bladderwort was attached by nylon filament fishing lines to an anchor (made of a sock filled with rocks) and to a Styrofoam ball to act as a buoy in the water. Three specimens of each species were placed in the swamp next to a rusting iron crane (site \#1). The remaining six bladderworts were positioned under a tree by another channel of water (site \#2). The light intensity was approximately the same at both sites. The second site was approximately 150 meters from the rusting crane, i.e. far enough from it 


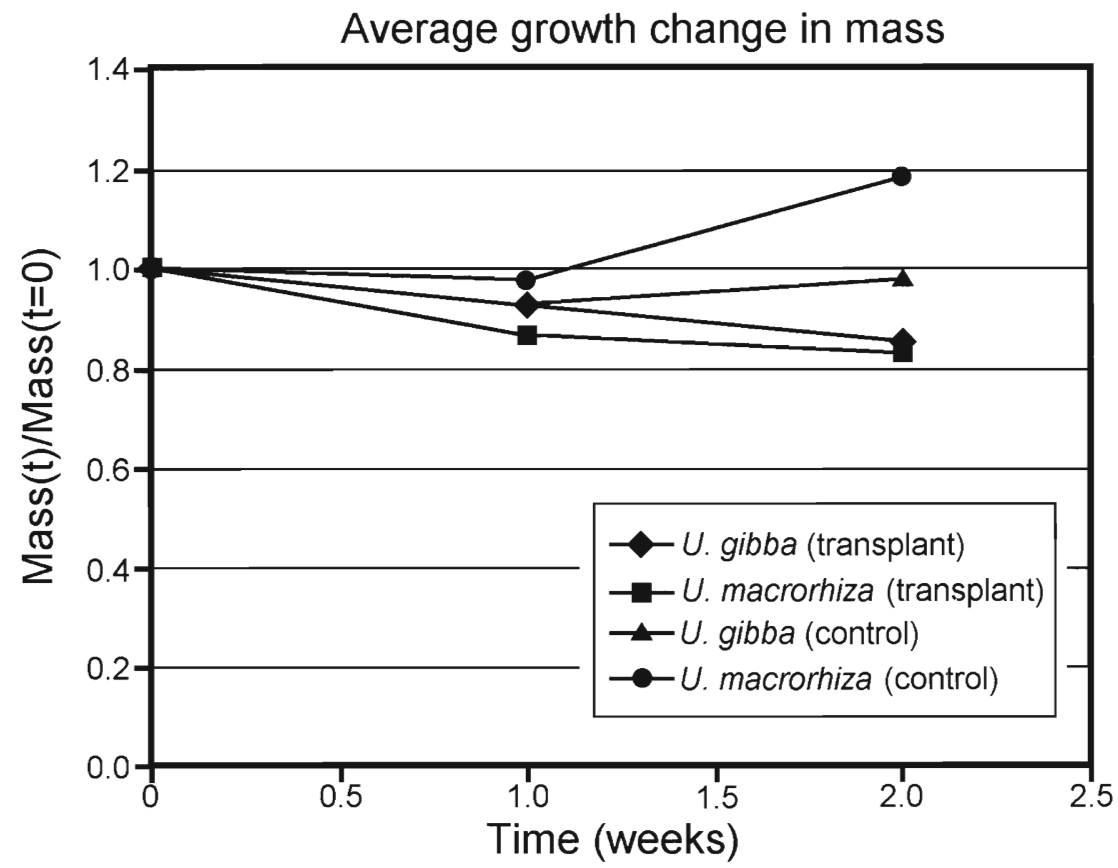

Figure 1: Average relative change in growth in mass for control and transplanted plants.

Average growth change in mass

\section{U. gibba with Copper}

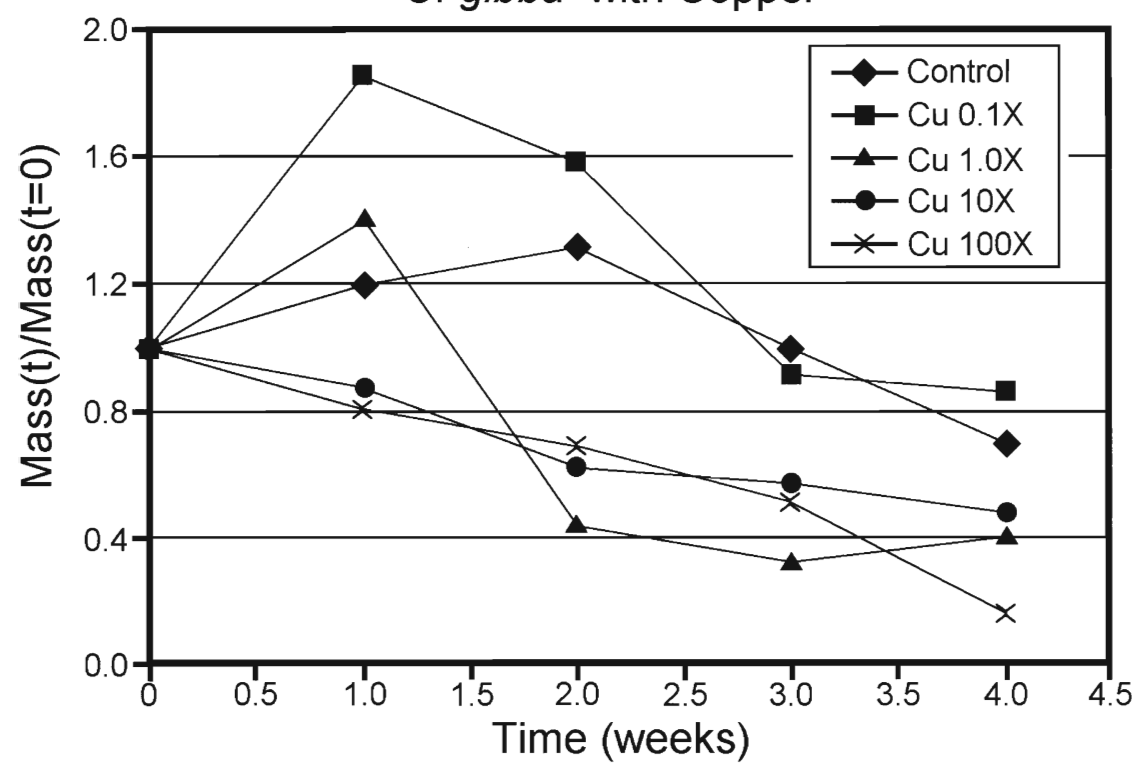

Figure 2: Relative change of $U$. gibba mass, in various copper concentrations. 
to probably not be significantly contaminated by it. These transplantation sites were visited every 2 weeks for 4 weeks total. On each visit, the bladderworts' mass was recorded.

For the laboratory experiments, three repetitions were set up about a week apart and each repetition was carried out for a total of 4 weeks. For each repetition, $U$. gibba and $U$. macrorhiza plants (from site \#1) were placed in $500 \mathrm{~mL}$ containers filled with $\mathrm{ddH}_{2} \mathrm{O}$ as controls; eight of each species were placed in $500 \mathrm{~mL}$ of $0.1 \mathrm{X}, 1.0 \mathrm{X}, 10 \mathrm{X}$ and $100 \mathrm{X}$ separate copper and iron solutions. (This scale was set by Raven (1971), where 1.0X normally yields healthy growth in plants, where 1.0X levels are $0.01 \mathrm{mg} \mathrm{L}^{-1}$ (for copper) and $1.0 \mathrm{mg} \mathrm{L}^{-1}$ (for iron)). Copper was dissolved into $\mathrm{ddH}_{2} \mathrm{O}$ in the form of cupric chloride $\left(\mathrm{CuCl}_{2} \bullet 2 \mathrm{H}_{2} \mathrm{O}\right)$ and iron in the form of ferric chloride $\left(\mathrm{FeCl}_{3}\right)$.

In order to ensure that no confounding factors affected the growth of the bladderworts and to emulate natural environmental conditions, the light intensity was adjusted in the lab. All plants were grown under wide spectrum fluorescent bulbs. Light levels in the growing area were 1000-2500 lux (total incident radiation) and $15-35 \mu \mathrm{mol} \mathrm{m} \mathrm{m}^{-2} \mathrm{~s}^{-1}$ PAR.

Since carbon dioxide levels in the swamps and marshes where the bladderworts are found are higher than those found in the $\mathrm{ddH}_{2} \mathrm{O}$ in the lab (McDermott \& Darnowski, 2001), $\mathrm{CO}_{2}$ was bubbled into the containers. The carbon dioxide source was a sucrose and yeast reactor per the description by Camilleri (1998).

The mass and length of the cultivated bladderworts were measured every week for a period of 4 weeks.

\section{Results}

The majority of sampling sites had $\mathrm{pH}<7$ and were shaded to $0.3-45 \%$ compared to direct sunlight. The $\mathrm{Cu}$ and Fe levels at the control site (site \#2) were $0.70 \mu \mathrm{g} \mathrm{Cu} \mathrm{L}^{-1}$ and $1.1 \mu \mathrm{g} \mathrm{Fe} \mathrm{L}^{-1}$, respectively. At the transplantation site (site \#1), they were $1.7 \mu \mathrm{g} \mathrm{Cu} \mathrm{L}^{-1}$ and $1.2 \mu \mathrm{g} \mathrm{Fe} \mathrm{L}^{-1}$, respectively. As shown in Figure 1, transplanted specimens in the higher $\mathrm{Cu}$ and $\mathrm{Fe}$ site had lower growth rates with respect to the controls.

In the laboratory, as ion concentrations increased, decreases in growth were observed. For example, both species usually had the highest growth rates in the control and 0.1X solutions, followed by the 1.0X solutions. Although most plants in 100X solutions declined, U. gibba survived in the 100X Cu solution and $U$. macrorhiza survived in the 100X Fe solution (see Figures 2-5).

\section{Discussion}

The hypothesis made at the beginning of this experiment was that the bladderworts' rate of growth would increase with the concentration of metal ions and then decrease after the optimal point was reached and the concentration became toxic. The observation that the two species were found in different areas of the sampling sites suggested that they had different preferences or living habitats. Accordingly, only $U$. gibba were found at site \#1 which contained high amounts of copper. Meanwhile, U. macrorhiza were found in other sites rich in iron.

As assumed, samples from site \#1 (old iron machine) and site \#5 (rusting iron dock) contained high $\mathrm{Fe}$ and $\mathrm{Cu}$ ion concentrations. The transplanted specimens at site $\# 1$ grew in an environment analogous to the $\mathrm{Fe} 10 \mathrm{X}-100 \mathrm{X}$ and $\mathrm{Cu}>100 \mathrm{X}$ solutions used in the laboratory experiments. Like the plants grown in these solutions, the transplants had low or no growth rates. On the other hand, the controls at site \#2 grew in an environment of moderate and non-toxic $\mathrm{Cu}$ and $\mathrm{Fe}$ levels and displayed normal growth rates.

In the laboratory studies, plants grown in the 0.1 and $1.0 \mathrm{X}$ solutions had the highest growth rates while very low growth and sometimes death occurred at $10 \mathrm{X}$ or $100 \mathrm{X}$ concentrations. Utricularia gibba survived in the concentrated $\mathrm{Cu}$ solution while $U$. macrorhiza did the same in high Fe solutions. Both species, however, died in high concentration solutions of the other respective ion. These results suggest that $U$. gibba and $U$. macrorhiza can adapt to environments rich in $\mathrm{Cu}$ and $\mathrm{Fe}$, respectively.

The data show that the growth rate of these two bladderwort species remained positive with increasing concentrations of $\mathrm{Cu}$ and $\mathrm{Fe}$ ions until the amounts became toxic. This conclusion corroborates findings published by several other researchers. For example, a study determined that the growth rate and biomass of $U$. vulgaris increased in concentrations of humic acids from 1- $4 \mathrm{mg}$ $\mathrm{L}^{-1}$ but are seriously inhibited in higher concentrations (Kosiba, 1992). In addition, the transplantation and laboratory experiments imply that $U$. gibba expresses tolerance to high concentrations of 
Average growth change in mass

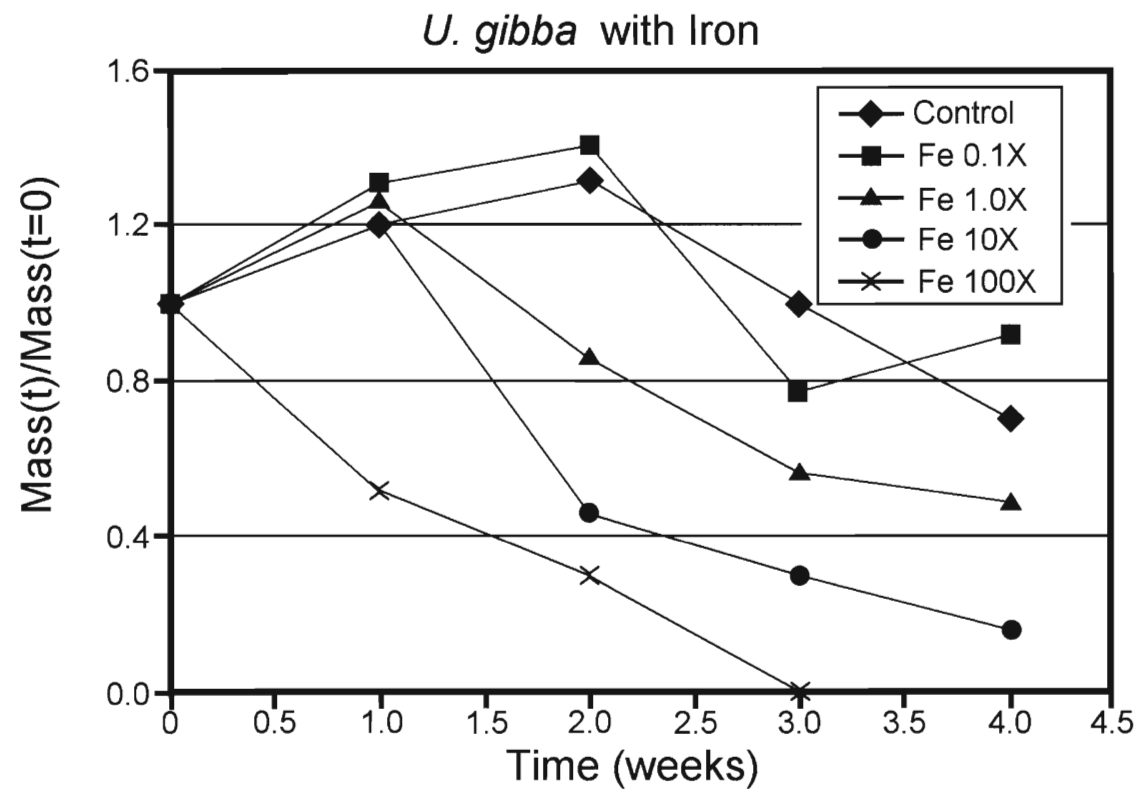

Figure 3: Relative change of $U$. gibba mass, in various iron concentrations.

Average growth change in mass

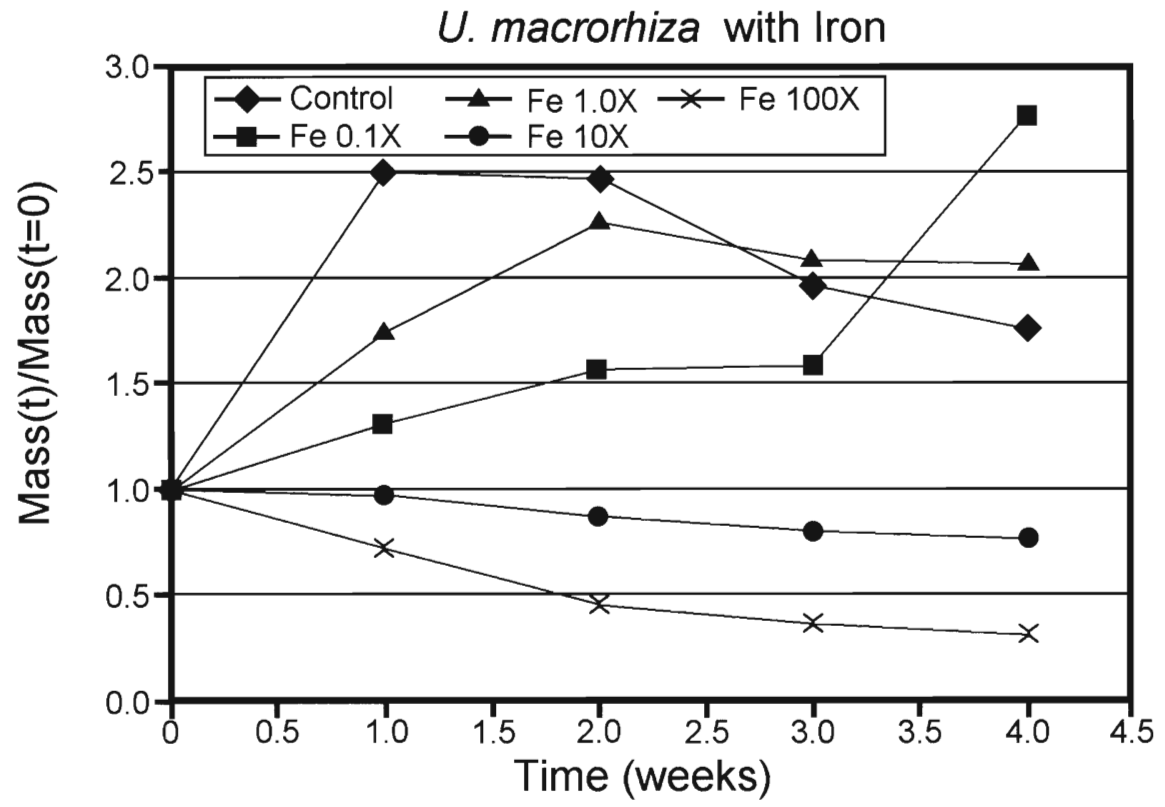

Figure 4: Relative change of U. macrorhiza mass, in various iron concentrations. 


\section{Average growth change in mass U. macrorhiza with Copper}

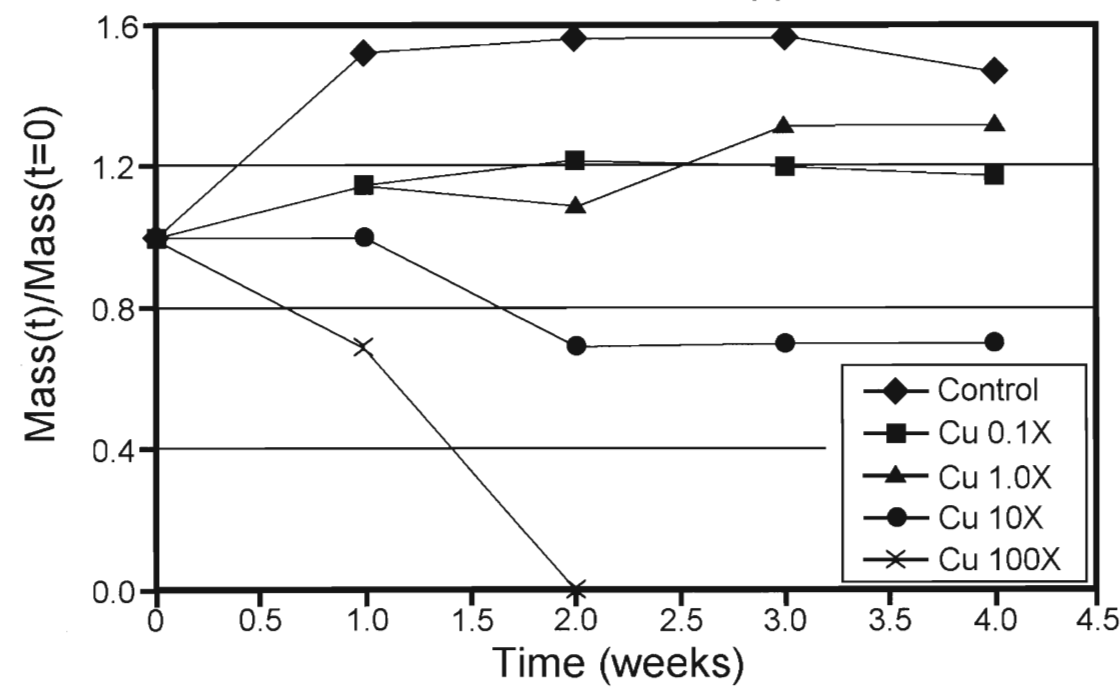

Figure 5: Relative change of $U$. macrorhiza mass, in various copper concentrations.

$\mathrm{Cu}$ while $U$. macrorhiza can survive in high Fe concentration environments.

Transplantation experiment specimens were surrounded by organic matter that may have affected growth (Kosiba, 1992) and may account for the slight difference in results between the transplantation and laboratory experiments. These results can be used in further research to explore whether bladderworts prefer acidic environments or gravitate towards them because they can outcompete other plants there.

Acknowledgements: Thanks to Andrew and Betsy McCown, Echo Hill Camp and Echo Hill Outdoor School, Matt McDermott for his previous research and the Middendorf Foundation for funding this project.

\section{References:}

Camilleri, T. 1998, Carnivorous Plants, Kangaroo Press, Australia.

D’Amato, P. 1998, The Savage Garden, Ten Speed Press, Berkeley.

Friday, L. 1992, Measuring Investment in Carnivory: Seasonal and Individual Variation in Trap Number and Biomass in Utricularia vulgaris L., New Phytologist 121/3:439-445.

Greenberg, A., Clesceri, L. and Eaton, A. 1992, Standard Methods for the Examination of Water and Wastewater, American Public Health Association, Washington, DC.

Jobson, R., Morris, E. and Burgin, S. 2000, Carnivory and nitrogen supply affect the growth of the bladderwort Utricularia uliginosa, Australian J. Bot. 48:549-560.

Knight, S. and Frost, T. 1991, Bladder Control in Utricularia macrorhiza: Lake-Specific Variation in Plant Investment in Carnivory, Ecology 72/2:728-723.

Kosiba, P. 1992, Studies on the Ecology Utricularia vulgaris L.: I. Ecological Differentiation of Utricularia vulgaris L. Population Affected by Chemical Factors of the Habitat, Ekologia Polska 40/2:147-192.

McDermott, M. and Darnowski, D. 2001, Abiotic Factors, Particularly $\mathrm{CO}_{2}$ Concentration, Affecting Carnivorous Plants from the Eastern Shore of Maryland. Carniv. Pl. Newslett. 31: 6774.

Raven, P. 1971, Biology of Plants, Worth Publishers, Inc., New York.

Schnell, D. 1976, Carnivorous Plants of the United States and Canada, J. F. Blair, Winston- Salem. 